\title{
Environmental assessment of Biorefinery processes for the valorization of lignocellulosic
} wastes into oligosaccharides.

Sara Gonzalez-Garcia*, Beatriz Gullón, Maria Teresa Moreira

Department of Chemical Engineering, School of Engineering, University of Santiago de Compostela. 15782-

Santiago de Compostela, Spain.

*Corresponding author: Tel.: +34 881816806; E-mail address: sara.gonzalez@usc.es

\section{Abstract}

9 One of the most relevant goals in the application of circular economy to the industrial activities is to convert low-value side streams into more valuable products. In this sense, the conversion of lignocellulosic biomass into biofuels and chemicals is a major challenge not only from the technological but also from the economic and environmental perspectives.

13 In this study, the production of pectin-derived oligosaccharides (POS) from sugar beet pulp (SBP), 14 promising candidates for prebiotic properties, was assessed from an environmental perspective using 15 the Life Cycle Assessment methodology under a cradle-to-gate approach. Two different scenarios at 16 pilot scale were considered: Scenario 1 based on conventional autohydrolysis at high temperature and 17 Scenario 2 based on enzymatic hydrolysis.

18 The outcomes of this environmental study are highly dependent on the production yield of the target 19 compounds (POS) and the valorisation strategy considered. In fact, the POS yield of the 20 autohydrolysis approach is around $20 \%$ higher in the enzymatic one. According to the results, 21 Scenario 1 reports the worst results when a functional unit based on the amount of valorised material 22 (100 kg of oven-dried SBP) is managed. However, the profile entirely changes when a unit based on 23 the economic revenue $(1 €)$ is considered. Therefore, attention should be paid on the selection of the 24 functional unit since decision making strategies should highly depend on it. 
26 Without waiting for the opportunity to conduct LCA of already-developed processes of the biorefinery

27 system, the development of new alternatives must be carried out with sustainability in mind and the 28 proposal of valorisation strategies for secondary streams should include the analysis of the 29 environmental impacts associated to each alternative, even at the pilot plant stage.

30 Keywords: environmental profile; life cycle assessment; pectin-derived oligosaccharides; prebiotics; 


\section{Introduction}

Sugar beet pulp is an abundant co-product from the sugar industry (Al-Tamimi et al., 2006; Zheng et al., 2013). Around 5 Mtons are produced in European countries (Ziemiński et al., 2014), of which nearly $20 \%$ is produced in Spain mainly for animal feed (Martínez et al., 2009a; Concha Olmos and Zúñiga Hansen, 2012).

The sustainable implementation and development of bio-processes in the short and medium-term is receiving special attention due to the fast depletion of fossil fuels, their fluctuating price as well as the increasing concerns on greenhouse gases (GHG) emission (Huisingh et al., 2015; Montazeri and Eckelman, 2015; Philp, 2015). Therefore, the current industry must then face the challenge to transform industrial low-value side products into more value-added materials (Pin et al., 2014; González-García et al., 2016; Van Uytvanck et al., 2014). In this sense, the implementation of the biorefinery scheme in the framework of the sugar beet industry must promote those innovation technologies that increase not only the yield and profitability of the processes but also that improve the environmental profile (Huisingh et al., 2015; González-García et al., 2016; Russell and Shiang, 2013).

Thus, sugar beet pulp (from now SBP) - a lignocellulosic source, could be considered a promising byproduct with potential valorisation in a biorefinery scheme due to its composition and abundance. In the sugar beet processing system, the main product is sucrose, which accounts for $10-12 \%$ of the total biomass processed. However, the analysis of the SBP composition also comprises $20-25 \%$ cellulose, $25-36 \%$ hemicelluloses (mainly arabinans), $20-25 \%$ pectin, $10-15 \%$ protein and $1-2 \%$ lignin (Concha Olmos and Zúñiga Hansen, 2012; Ziemiński et al., 2014).

Although feed formulation is the main use of SBP (Concha Olmos and Zúñiga Hansen, 2012), other applications are also possible (Ziemiński et al., 2014), such as in the production of composites (Liu et al., 2005), galacturonic acid and arabinose (Leijdekkers et al., 2013) or biogas (Ziemiński et al., 2014) as well as in the papermaking industry due its low lignin content (Bellido et al., 2015). Nevertheless, other biorefinery promising alternatives focused on the production of biofuels are still under 
development (Leijdekkers et al., 2013). In recent studies, SBP has been evaluated as a potential 59 source for the production of functional carbohydrates, paying attention to neutral and acidic 60 oligosaccharides by means of a direct enzymatic saccharification treatment (Concha Olmos and 61 Zúñiga Hansen, 2012; Martínez et al., 2009a).

62 Oligosaccharides are attracting increasing interest as prebiotic functional food ingredients (Rastall, 63 2010; Patel and Goyal, 2011) as they may bestow health benefits on the host associated with the 64 modulation of microbiota (Martínez et al., 2009b), especially pectin-derived oligosaccharides (POS) 65 (Rastall, 2010; Patel and Goyal, 2011). POS can be produced from waste biomass or low-cost 66 byproducts by applying a selective fractionation based on physical, chemical and enzymatic methods 67 (Sun and Hughes, 1998; Patel and Goyal, 2011).

68 To the best of our knowledge, only one LCA study has been published with special focus on the 69 environmental footprints of different production schemes of soluble saccharides of polymeric and 70 oligomeric nature from woody residual streams (González-García et al., 2016). In this work, the 71 assessment of the environmental impacts associated to the valorisation of SBP from the sugar refining 72 industry for the production of POS was performed. To do this, a Life Cycle Assessment (LCA) was 73 undertaken to i) analyse two valorisation scenarios based on different extraction routes considering 74 SBP as raw material and based on experiments and protocols carried out at semi-pilot scale, ii) 75 identify the environmental hotspots responsible of the largest impacts, and iii) define the best 76 valorisation route in terms of minimal environmental impacts. This environmental methodology 77 considers all the resources (mass and energy balances) required to make a product, the wastes 78 generated as well as the environmental burdens associated with the product (Goedkoop et al., 2008). 79 In addition, this tool can provide useful information to industry and policy makers on decision making 80 towards the consideration of sustainability in processes under development. 
83 Life Cycle Assessment (LCA) methodology in compliance with the principles established by ISO

84 standards (ISO 14040, 2006) was performed from an attributional perspective in
85 production of pectin-derived oligosaccharides (POS) from sugar beet pulp (SBP).

\section{$86 \quad 2.1$ Goal and scope definition}

87 This study aims to assess the environmental performance of different extraction routes of SBP from 88 the sugar industry to obtain a POS extract with high content in arabino-oligosaccharides and 89 oligogalacturonides. Side-streams are also derived from the system which could be used for further

- Scenario 1 based on the autohydrolysis of SBP (hydrothermal processing under nonisothermal conditions) performed in a stirred and pressurised stainless steel reactor at $163^{\circ} \mathrm{C}$ (Martínez et al., 2009b)

A cradle-to-gate approach was considered in the scenarios under assessment that is, considering the extraction of raw materials to produce the required inputs and the production of POS but not the use and/or final disposal phase of POS after use. Among the processes considered throughout the production life cycles of both valorising schemes, centrifugation, membrane concentration and freezedrying are performed after the extraction phase. Considering that SBP is a co-product of the sugar refining process, the background process of SBP production was excluded from the assessment. Thus, derived environmental impacts were entirely allocated to the sugar.

The LCA functional unit must be selected carefully to allow comparisons between the valorising systems under study. Thus, the functional unit is defined as $100 \mathrm{~kg}$ of oven-dried SBP at the factory gate, provided by a local pulp factory (Martínez et al., 2009b). 


\subsection{Description of the SBP valorisation scenarios}

Each valorisation scenario destined to the production of POS was divided in five different subsystems which are depicted in Figure 1 and Figure 2 for Scenario 1 and Scenario 2 respectively: autohydrolysis (SS1.1), enzymatic hydrolysis (SS1.2), centrifugation (SS2), concentration (SS3), diafiltration (SS4), freeze-drying (SS5) and wastewater treatment (SS6). The subsystems were assessed from the production of raw materials (resources) up to the final product at the pilot plant gate. As indicated above, further processing and transport activities were excluded from the system boundaries as well as the activities related with the production of the SBP used as raw material.

115 In both scenarios, SBP (70-72\% moisture) was provided by a local pulp factory, homogenised in a 116 single lot to avoid compositional differences, and stored in polyethylene bags at $-18^{\circ} \mathrm{C}$ until use

$117<$ Figure 1 around here>

$118<$ Figure 2 around here>

119 Scenario 1 - Autohydrolysis treatment

20 SBP is subjected an aqueous processing (autohydrolysis treatment) with tap water in a ratio of $12 \mathrm{~g}$ 121 water per g dry pulp. In this work, the reactor was heated up to achieve a maximum temperature of $122163^{\circ} \mathrm{C}$, the optimum conditions reported for pectic-oligomers production from SBP (Martínez et al. 123 2009a). The autohydrolysis treatment permits the selective breakdown of pectic polymers to give 124 valuable soluble hydrolysis products such as pectic-oligomers (POS) and a solid fraction rich in 125 cellulose and lignin. At the end of treatment, the reactor was rapidly cooled to $60^{\circ} \mathrm{C}$ for $12 \mathrm{~min}$, and the 126 liquors were separated from the spent solids by centrifugation. Table 1 shows the composition of the 127 autohydrolysis liquors.

$128<$ Table 1 around here> 
Scenario 2 - Enzymatic Hydrolysis treatment

Based on previous studies (Martínez, 2009b), POS mixtures were obtained by enzymatic processing of SBP using commercial enzymes (Celluclast $1.5 \mathrm{~L}$ cellulases from Trichoderma reesei and Viscozyme 1.5L endopolygalacturonases from Aspergillus aculeatus). The experimental conditions considered were the following: water/solid ratio of $12 \mathrm{~g} / \mathrm{g}$ dry pulp, endopolygalacturonase/solid ratio of $10 \mathrm{U} / \mathrm{g}$, cellulase/endopolygalacturonase ratio of $0.725 \mathrm{FPU} / \mathrm{U}$ and reaction time of $12.8 \mathrm{~h}$. At the end of process, liquors were separated by centrifugation. The experiments were carried out at $37^{\circ} \mathrm{C}$ in Erlenmeyer flasks with orbital agitation (150 rpm). Table 2 shows the composition of the hydrolysates obtained by enzymatic treatment.

139 The autohydrolysis and enzymatic liquors were treated for purification and concentration using a 140 membrane processing unit in order to get a stream rich on POS. The experiments were carried out 141 using a polymeric spiral membrane with molecular weight cut-off of $1 \mathrm{kDa}$ and pressure operation of 8 142 bar. The processing was carried out at room temperature.

143 The processing started with the concentration of both streams to achieve a volume/concentration 144 (VCR) ratio of 5. For additional refining, water was added to the retentate to reach initial volume, and 145 the resulting solution was concentrated again (discontinuous diafiltration) to achieve the same VCR. At 146 the end of processing, two streams were obtained, a retentate rich on POS and a permeate rich on 147 monosaccharides and other non-saccharide compounds. Finally, the retentate stream was freeze148 dried.

\subsection{Inventory data acquisition and allocation approach}


151 A reliable environmental assessment requires the collection of high value Life Cycle Inventory (LCI) data. In this study, inventory data for the foreground system (direct inputs and outputs for each stage) such electricity requirements (estimated with power and operational data from the different units: reactors, centrifuges, membranes, orbital shakers and freeze-dryers) as well as use of chemicals, enzymes and water were average data of the pilot plant (primary data). A summary of the primary data is displayed in Table $\mathbf{3}$ for the different valorisation scenarios.

$<$ Table 3 around here $>$

158 Concerning the background system, the inventory data corresponding to the production of the different 159 inputs to the systems (electricity, chemicals and tap water) and the wastewater treatment process 160 were taken from Ecoinvent database $\AA$ and data for enzyme production were found in Nielsen et al. 161 (2007).

162 All the scenarios under assessment are multi-outputs systems with more than one product. Allocation 163 of the environmental impacts is required for multi-functional processes and the selection of an 164 allocation approach can have a strong effect on the results. According to the functional unit chosen 165 (100 kg of oven-dried SBP), no allocation procedure was required since it is referred to the raw 166 material processed per batch instead of to the amount of products obtained. The economic value of all 167 the bioproducts differs significantly, which should motivate the use of an economic based approach. 168 Therefore, an alternative functional unit in terms of economic value was considered based on the 169 expected economic revenues of the bioproducts obtained in each scenario. Table 4 reports the market 170 prices considered for the different co-products and the expected net revenue.

$171<$ Table 4 around here> 
174 LCA evaluates the environmental burdens by identifying resource and energy consumption as well as

1 2 3 emissions to different environmental compartments associated to the life cycle of the process under assessment, including the identification of priority areas to implement improvement actions (ISO 14040, 2006). The characterisation factors reported by the Centre of Environmental Science of Leiden University - CML 2001 method (Guinée et al. 2001) v2.05 were considered in this study for the analysis. The following impact categories were evaluated: abiotic depletion potential (ADP), acidification potential (AP), eutrophication potential (EP), global warming potential (GWP), photochemical oxidation potential (POFP), ozone layer depletion potential (ODP), human toxicity potential (HTP), terrestrial ecotoxicity potential (TEP), freshwater aquatic ecotoxicity potential (FEP) and marine aquatic ecotoxicity potential (MEP). Moreover, SimaPro 8.02 was the software used for the computational implementation of the LCl (PRé Consultants, 2016).

\section{Results and discussion}

186 The purpose of this work is to evaluate the environmental performance of two different valorising routes for the production of POS from sugar beet pulp as raw material under a biorefinery perspective. 188 Both valorising schemes involve the production of POS together with a residual stream (solid fraction) 189 from the hydrolysis reactors, the latter presents a composition rich in valuable products - such as 190 cellulose, hemicellulose, lignin and uronic acids .

191 The environmental assessment in terms of characterisation results obtained for both schemes is 192 displayed in Table 5. As previously indicated, the production of SBP, the main raw material, was 193 excluded from the study because it was managed as a waste stream from sugar factories. Thus, 194 environmental burdens derived from sugar processing are totally allocated to the main product of the 195 production systems, i.e. sugar.

$196<$ Table 5 around here>

197 According to the environmental results reported, remarkable differences can be identified between both valorising schemes of SBP for the production of POS, which should be directly related with 
199 differences on the production systems. Although they share a number of stages in common

1

(centrifugation - SS2, concentration - SS3, diafiltration - SS4, freeze-drying - SS5 and wastewater treatment - SS6), the main difference between both routes is focused on the first stage or subsystem, that is the hydrolysis of the SBP (SS1.1 and SS1.2 for scenarios 1 and 2, respectively). In Scenario 1, it is a hydrothermal processing under non-isothermal conditions carried out at high temperature $\left(163^{\circ} \mathrm{C}\right)$. On the contrary, Scenario 2 considers an enzymatic step based on the use of a cocktail of enzymes at moderate temperature $\left(37^{\circ} \mathrm{C}\right)$. This fact involves differences on the electricity requirements, being 5600 times larger in Scenario 1 than Scenario 2. However, Scenario 2 requires enzymes whose production also entails energy consumption (Nielsen et al., 2007). Accordingly, Scenario 1 reports the worst environmental results in most categories except ODP, HTP, MEP and TEP. A detailed analysis of these results will be discussed below.

Contributions per subsystems involved

Figure 3 and Figure 4 displays the distribution of environmental burdens per subsystems involved in the production chains for Scenarios 1 and 2, respectively.

<Figure 3 around here>

$<$ Figure 4 around here>

According to Figure 3, the majority of the environmental burdens associated with Scenario 1 are related to the freeze-drying step (SS5) and the autohydrolysis stage (SS1.1). Freeze-drying process requires electricity consumption in order to obtain the final product (rich on POS and with low content on monosaccharides) while autohydrolysis is also energy intensive since the reactor operates at $163^{\circ} \mathrm{C}$. Both subsystems are responsible (on average) for $69 \%$ and $20 \%$ of the total contributions, respectively (see Figure 3) and the difference in energy requirement is very relevant: 3.5 times higher in SS5 than in SS1.1 (Table 3). The equipment used in the subsequent steps (centrifuge and membranes) reports the lowest amounts of electricity and therefore, their contributions to the environmental profile is negligible regardless the impact category. 
224 Concerning Figure 4, modifications on the environmental profile can be identified. Once again SS1.2

1

2225

3

4226

6227

7

228 and SS5 are the steps responsible for the majority of contributions to environmental impacts although with differences on the relative values and categories. SS5 is the environmental hotspot in all the categories with contributions ranging from $53 \%$ to $80 \%$ except in terms of MEP where SS1.2 is the main contributing subsystem with a contributing ratio of $74 \%$. Enzymes, acetate and electricity production are the processes behind this impact.

If the source of the environmental burdens derived from SS1.2 is assessed in more detail, two inputs are identified as major responsible of impacts: the production of the enzyme cocktail for the enzymatic hydrolysis and the production of acetate for $\mathrm{pH}$ control. Figure 5 displays the distribution of impacts derived from SS1.2 between the involved processes and, in line with the results, the production of acetate should be an environmental key factor, being responsible of the majority of the impacts in all the categories with ratios ranging from $54 \%$ to $88 \%$ except for MEP and TEP, where the production of the enzymes required for the hydrolysis contribute with $98 \%$ and $79 \%$ of the total impacts.

$<$ Figure 5 around here $>$

239 Total electricity requirements per batch in Scenario 2 are only $13 \%$ of the electricity consumed in 240 Scenario 1 and enzymatic hydrolysis step reports the lowest energy requirements followed by SS2, 241 SS3, SS4 and SS5, However, in Scenario 1 the highest electricity requirement is also observed in SS5 242 followed by SS1.1, SS3, 224 and SS2. Figure 6 displays the distribution of electricity requirements 243 between the subsystems directly involved in the valorising systems, excluding SS6 since the 244 wastewater treatment plant is beyond the premises of the manufacture plant.

$246<$ Figure 6 around here> 
Alternative functional unit and allocation strategies

According to the results reported so far, Scenario 1 presents much higher environmental burdens than Scenario 2 in six impact categories, excluding ODP, HTP, MEP and TEP, which considerably depend on the burdens associated to the enzyme production. These results are related to a functional unit based on the amount of SBP used: $100 \mathrm{~kg}$ of SBP. This functional unit can be considered useful when valorising systems are being analysed and where multiple by-products are obtained since it corresponds to the amount of valorised material per batch (Pérez-López et al., 2014; González-García et al., 2016). Nevertheless, the amount of valuable by-products, which also present different market prices, depends on the scenario. Therefore, the potential revenue obtained per scenario should be different depending on the valorising strategy. The selection of the functional unit to report the results has just been previously discussed in numerous studies where biosystems have been environmentally analysed (Kim and Dale, 2006; Pérez-López et al., 2014; González-García et al., 2016). According to these studies, special attention must be paid on the selection of the functional unit in order to report the environmental profiles since the decision strategies highly depend on it.

For that reason, an alternative functional unit based on the potential economic benefit expected from each valorisation scenario could be of interest. In addition, an allocation procedure was also proposed here considering an economic allocation approach. The alternative functional unit proposed is $1 €$ of economic revenue. Market prices available in the literature (Mercopress, 2006; Marketing study, 2009; Sigma-Aldrich, 2016) were managed and presented in Table 4.

Figure 7 displays the comparative profile between both scenarios considering $1 €$ of economic revenue as functional unit and it considerably changes in comparison with the profile corresponding to a functional unit based on the amount of processed biomass per batch. According to the results reported, Scenario 1 should involve the lowest impacts in all the categories under study. The reductions on the impacts should be remarkable in terms of MEP and TEP, where the enzymatic treatment based scenario reports 3.8 and 1.6 times higher burdens than Scenario 1. Both impact 
273 categories are significantly affected by the contributions from the enzymatic hydrolysis subsystem

1

2

3

4

5

6

7

8276

9

10

11

(SS1.2) as depicted in Figure 4, being the enzyme production the main responsible factor (see Figure 5).

$<$ Figure 7 around here $>$

If an economic allocation is considered on the basis of the production of POS and other by-products with economic value, the partition of the environmental burdens between the different products should be carried out taking into account the allocation factors reported in Table 4. Thus, $96.9 \%$ and $95.6 \%$ of the impacts reported in Table 5 for Scenario 1 and 2 respectively should be allocated to POS. The majority of burdens should correspond to the production of POS and negligible burdens should be allocated to the remaining by-products (except the uronic acids), mostly due to the lower price of the by-products (lignin, cellulose and hemicellulose). Around $3.1 \%$ and $4.4 \%$ of the impacts should be allocated to the uronic acids. Therefore, when referring to the amount of POS produced, the environmental behaviour should be similar to the results reported in Figure 7, presenting Scenario 2 the worst profile.

\section{Comparison with related studies}

According to the literature revised, no LCA studies are available for prebiotic products obtained from SBP. González-García et al. (2016) analysed the production of soluble saccharides of polymeric and oligomeric nature (POHs) from residual woody chips. In that study, different valorising routes were environmentally evaluated which derived on the production of multiple by-products (lignin, cellulose, monosaccharides, antioxidant extract, levulinic acid and formic acid) together with $\mathrm{POHs}$. The results 
determined the best valorising route from an environmental perspective and identified the critical subsystems or production stages. Thus, purification activities which involve concentration and freezedrying as well as autohydrolysis were identified as the major responsible of environmental burdens. In our study, hydrolysis and freeze-drying were also identified as environmental hotspots specifically due to the high electricity requirements and enzymes (and chemicals) production. Thus, special attention and improvements should be paid on both activities since, regardless the valorisation route and raw material processed, are identified as critical steps.

\section{Conclusions}

304 The valorisation of refinery side-stream products is receiving special attention and it is a challenge of 305 today's industry. This study has analysed two different valorising routes of sugar beet pulp, by-product 306 of the sugar industry, with the aim of obtaining POS, a potential product with prebiotic properties. 307 According to the results, special attention must be paid on two specific stages: the hydrolysis and the 308 freeze-drying of the final product. However, the one based on an enzymatic treatment should report 309 the best environmental results regardless the functional unit considered for analysis. The enzymatic 310 based hydrolysis involved the requirement of enzymes whose production also requires energy. In 311 contrast to the conventional hydrolysis carried out at high temperature, the consumption of electricity 312 is 5600 times lower. The valorising sequences analysed in this study appear to be attractive options to 313 produce high-added value products with multiple applications. According to the outcomes, further 314 research should be focused in order to improve the current valorising techniques at pilot scale.

\section{Acknowledgements}

316 This research was supported by a project granted by BBVA programme "2015 edition of the BBVA 317 Foundation Grants for Researchers and Cultural Creators" (2015-P0027) and partially funded by the 318 Spanish Ministry of Economy and Competitiveness (2G-Sugars project, PCIN-2015-031). Dr. S. 319 González-Garcia and Dr. B. Gullón would like to express her gratitude to the Spanish Ministry of Economy and Competitivity for financial support (Grant references RYC-2014-14984 and FPDI-2013- 
321 17341, respectively). The authors belong to the Galician Competitive Research Group GRC 2013-032,

1

232

3

4

6323

7

8

10324

11

12

13

14325

15

16

17

18

19

20

21

22

23

24

25

26

27

28

29

30

31

32

33

34

35

36

37

38

39

40

41

42

43

44

45

46

47

48

49

50

51

52

53

54

55

56

57

58

59

60

61

62

63

64

65

programme co-funded by FEDER as well as to CRETUS (AGRUP2015/02). 
Al-Tamimi, M. A. H. M., Palframan, R. J., Cooper, J. M., Gibson, G. R., Rastall, R. A. (2006). In vitro Fermentation of Sugar Beet Arabinan and Arabino-oligosaccharides by the Human Gut Microflora. J. Appl. Microbiol. 100, 407-414.

Bellido, C., Infante, C., Coca, M., González-Benito, G., Lucas, S., García-Cubero, M.T., 2015. Efficient acetone-butanol-ethanol production by Clostridium beijerinckii from sugar beet pulp. Bioresour. Technol. 190, 332-338.

Concha Olmos, J., Zúñiga Hansen, M.E. (2012). Enzymatic depolymerization of sugar beet pulp: Production and characterization of pectin and pectic-oligosaccharides as a potential source for functional carbohydrates. Chem. Eng. J. 192, 29-36.

Ecoinvent database ${ }^{\circledR}(2016)$. http://www.ecoinvent.org/database (accessed October 2015).

Goedkoop M., Heijungs, R., Huijbregts, M., de Schryver, A., Struijs, J., Van Zelm, R. (2009). ReCiPe 2008, A Life Cycle Impact Assessment Method Which Comprises Harmonised Category Indicators at the Midpoint and the Endpoint Level. Report: Characterisation, first ed.; May 2013. http://www.lcia-recipe.net (accessed October 2015).

Gonzalez-Garcia, S., Gullón, B., Rivas, S., Feijoo, G., Moreira, M.T. (2016). Environmental performance of Biomass refining into High-added value compounds. J. Clean. Prod. 120,170-180.

Guinée JB, Gorrée M, Heijungs R, Huppes G, Kleijn R, de Koning A, van Oers L, Wegener A, Suh S, Udo de Haes HA., 2001. Life Cycle Assessment. An operational guide to the ISO standards. Centre of Environmental Science, Leiden, The Netherlands.

Huisingh, D., Zhang, Z., Moore, J.C., Qiao, Q., Lif, Q. (2015). Recent advances in carbon emissions reduction: policies, technologies, monitoring, assessment and modeling. J. Clean. Prod. $103,1-12$.

ISO 14040, 2006. Environmental Management - Life Cycle Assessment - Principles and 350 Framework. Second ed. Geneva, Switzerland. 
Leijdekkers, A.G.M., Bink, J.P.M., Geutjes, S., Schols, H.A., Gruppen, H. (2013). Enzymatic saccharification of sugar beet pulp for the production of galacturonic acid and arabinose; a study on the impact of the formation of recalcitrant oligosaccharides. Bioresour. Technol. 128, 518-525.

Liu, L.C., Fishman, M.L., Hicks, K.B., Liu, C.-K. (2005). Biodegradable composites from sugar beet pulp and poly(lactic acid). J. Agr. Food Chem. 53, 9017-9022.

Marketing study (2009). Marketing Study for Biomass Treatment Technology (October 2009). Techical Appendix 3- Products and Markets.

Martínez, M., Gullón, B., Yáñez, R., Alonso, J.L., Parajó, J.C. (2009a). Direct Enzymatic Production of Oligosaccharide Mixtures from Sugar Beet Pulp: Experimental Evaluation and Mathematical Modeling. J. Agric. Food. Chem. 57, 5510-5517.

Martínez, M., Gullón, B., Schols, H.A., Alonso, J.L., Parajó, J.C. (2009b). Assessment of the production of Oligomeric compounds from Sugar beet pulp. Ind. Eng. Chem. Res. 48, 4681-4687.

Montazeri, M., Eckelman, M.J. (2015). Life Cycle Assessment of Catechols from Lignin Depolymerization. ACS Sustainable Chem. Eng. DOI: 10.1021/acssuschemeng.5b00550.

Nielsen, P.H., Wenzel, H., 2007. Environmental assessment of Ronozyme (R) p5000 CT phytase as an alternative to inorganic phosphate supplementation to pig feed used in intensive pig production. Int. J. Life. Cycle. Assess. 12(7), 514-520.

Patel, S., Goyal, A. (2011). Functional oligosaccharides: production, properties and applications. World. J. Microbiol. Biotechnol. 27, 1119-1128.

Pérez-López, P., Balboa, E.M., González-García, E.M., Domínguez, H., Feijoo, G., Moreira, M.T., 2014. Comparative environmental assessment of valorization strategies of the invasive macroalgae Sargassum muticum. Bioresource Technology 161: 137-148

Philp, J. (2015). Balancing the bioeconomy: supporting biofuels and bio-based materials in public policy. Energy Environ. Sci. 8, 3063-3068. 
Pin, J.M., Guigo, N., Mija, A., Vincent, L., Sbirrazzuoli, N., van der Waal, J.C., de Jond, E. (2014). Valorization of Biorefinery Side-Stream Products: Combination of Humins with Polyfurfuryl Alcohol for Composite Elaboration. ACS Sustainable Chem. 2, 2182-2190.

PRé Consultants, 2016. http://www.pre.nl

Rastall, R.A. (2010). Functional oligosaccharides: application and manufacture, Annu. Rev. Food Sci. Technol. 1 (2010) 305-339

Russell, D.A.M., Shiang, D.L., 2013. Thinking about More Sustainable Products: Using an Efficient Tool for Sustainability Education, Innovation, and Project Management To Encourage Sustainability Thinking in a Multinational Corporation. ACS Sustainable Chem. 1, 2-7.

Sigmaaldrich, 2016. www.sigmaaldrich.com. Accessed June 2016.

Sun, R., Hughes, S. (1998). Fractional extraction and physico-chemical characterization of hemicelluloses and cellulose from sugar beet pulp. Carbohydr. Polym. 36, 293-299.

Van Uytvanck, P.P., Hallmark, B., Haire, G., Marshall, P.J., Dennis, J.S. (2014). Impact of Biomass on Industry: Using Ethylene Derived from Bioethanol within the Polyester Value Chain. ACS Sustainable Chem. 2, 1098-1105.

Zheng, Y., Lee, C., Yu, C., Cheng, Y., Zhang, R., Jenkins, B.M., VanderGheynst, J.S. (2013). Dilute acid pretreatment and fermentation of sugar beet pulp to ethanol. Appl. Energy 105, 1-7.

Ziemiński, K., Romanowska, I., Kowalska-Wentel, M., Cyran, M. (2014). Effects of 393 hydrothermal pretreatment of sugar beet pulp for methane production. Bioresour. Technol. 166, 187394193. 


\section{Dr. D. Huisingh}

Center for Clean Products and Clean Technologies, University of Tennessee

311 Conference Center Building

Knoxville

TN 37996-4134, USA

Email: dhuising@utk.edu

Santiago de Compostela, $12^{\text {th }}$ July 2016

\section{Dear Dr. Huisingh:}

We are pleased to enclose the revision of our original manuscript entitled "ENVIRONMENTAL ASSESSMENT OF BIOREFINERY PROCESSES FOR OLIGOSACCHARIDE PRODUCTION INTEGRATED TO THE SUGAR BEET INDUSTRY” by S. González-García, B. Gullón and MT. Moreira, which can hopefully be published in Journal of Cleaner Production. This paper has not been previously published, in whole or in part, and is not under consideration by any other journal.

A challenge of today's industry is to convert low-value side streams into more valuable products. In this sense, the conversion of lignocellulosic biomass into fuels and chemicals represents not only scientific but also economic and technical challenges, covering different fields of chemical and environmental engineering.

In this study, the production of pectin-derived oligosaccharides (POS) - promising candidates for prebiotic properties, from sugar beet pulp (SBP) - a by-product of the sugar industry very abundant in Europe, has been assessed from an environmental perspective using the Life Cycle Assessment methodology (cradle-to-gate approach). Two different scenarios have been designed at pilot scale: Scenario 1 based on conventional autohydrolysis at high temperature and Scenario 2, based on enzymatic hydrolysis.

The outcomes of this environmental study are highly dependent on the production yield of the target compounds (POS) and the valorisation route followed. In fact, POS yield is around 20\% higher in the autohydrolysis approach than in the enzymatic one. Finally, to keep the biorefinery options sound from an environmental perspective, it is mandatory to take into account the impacts associated to the valorisation of secondary streams, even at the pilot plant stage. Production.

We hope that this work is appropriate for publication in Journal of Cleaner Yours sincerely,

$$
\text { Sara Sonzález Yarcía }
$$


Figure 1. System boundaries and process chain under study corresponding to the Scenario 1 Autohydrolysis treatments. Processes marked in black were excluded from the system boundaries.

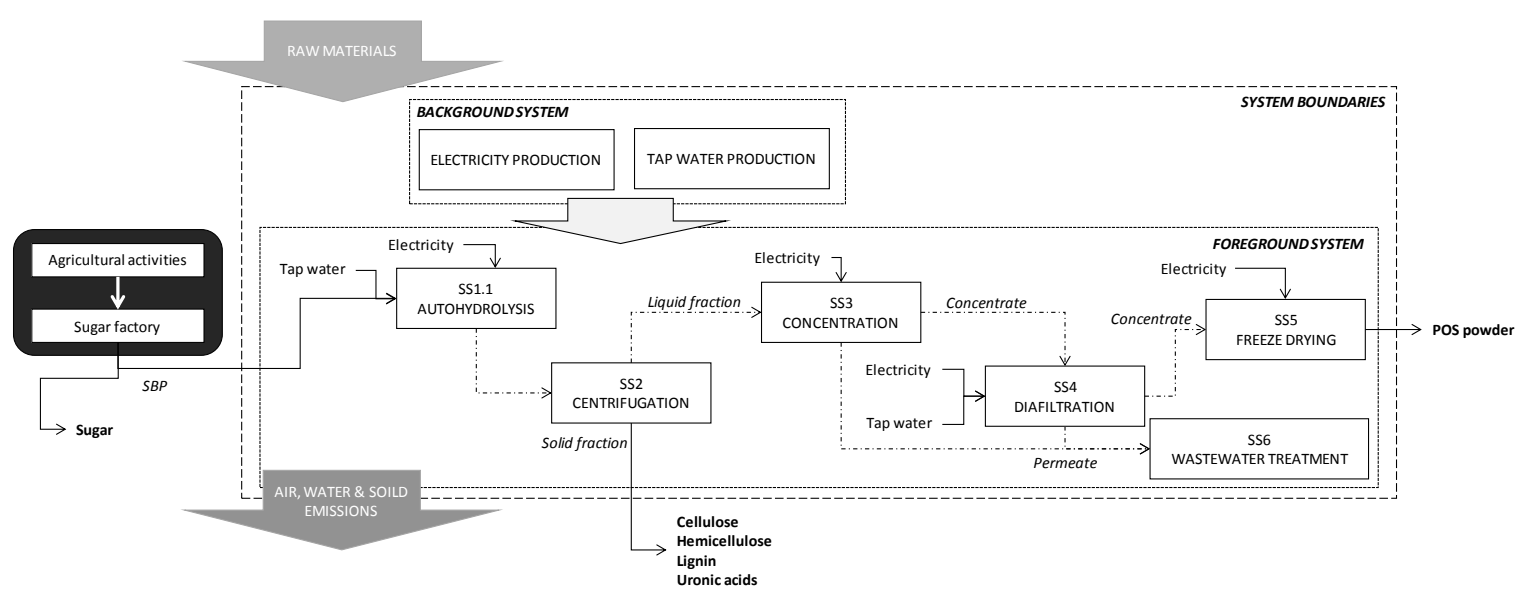

Figure 2. System boundaries and process chain under study corresponding to the Scenario 2 Enzymatic Hydrolysis treatment. Processes marked in black were excluded from the system boundaries.

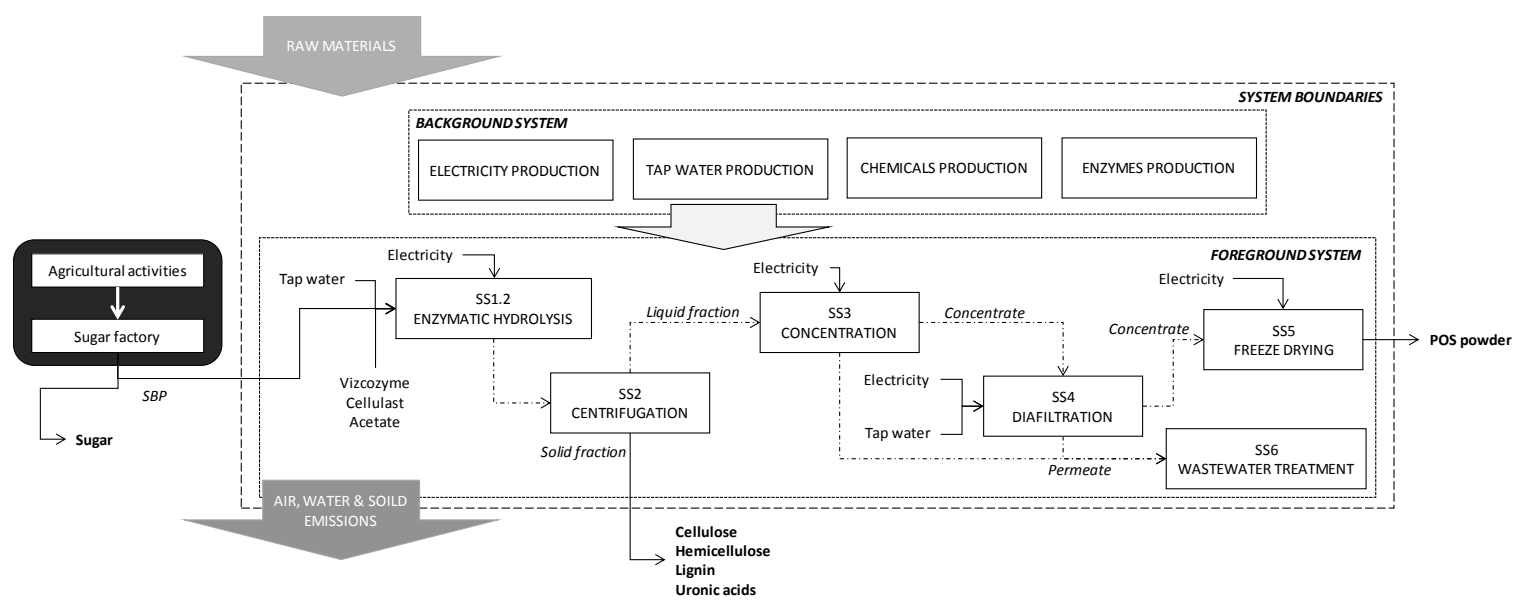


Figure 3. Distribution of environmental impacts per subsystems involved in Scenario 1. Acronyms: abiotic depletion potential (ADP), acidification potential (AP), eutrophication potential (EP), global warming potential (GWP), ozone layer depletion potential (ODP), human toxicity potential (HTP), freshwater aquatic ecotoxicity potential (FEP), marine aquatic ecotoxicity potential (MEP), terrestrial ecotoxicity potential (TEP) and photochemical oxidation potential (POFP),

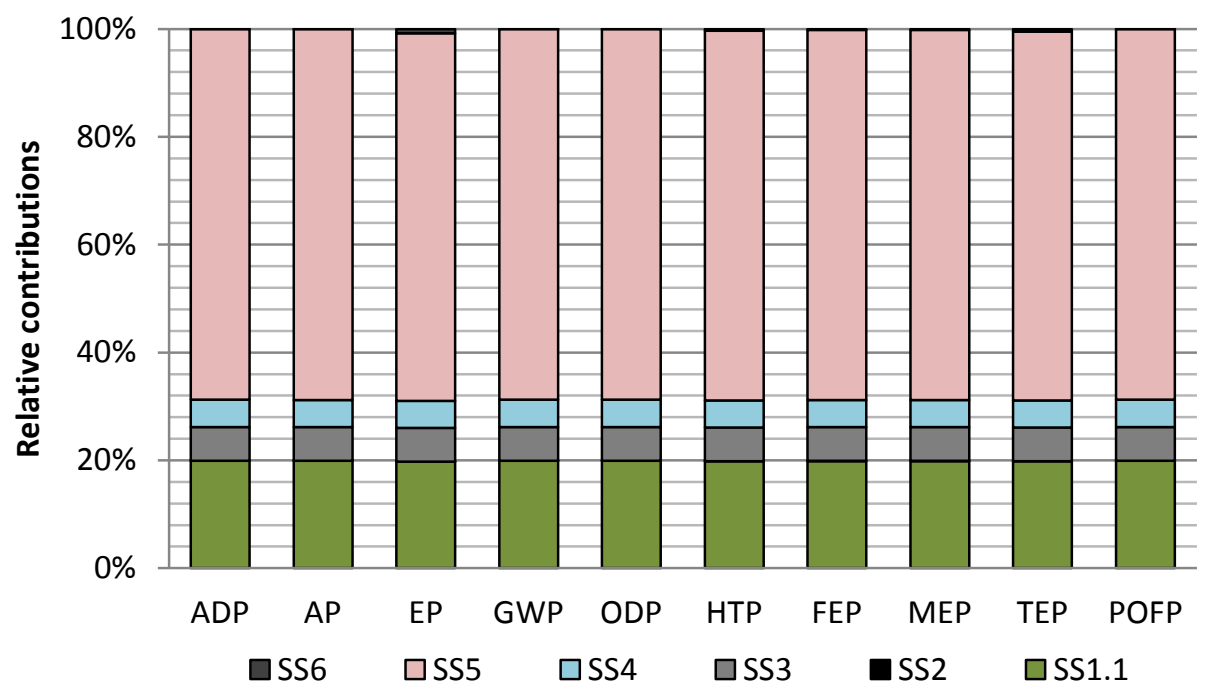

Figure 4. Distribution of environmental impacts per subsystems involved in Scenario 2. Acronyms: abiotic depletion potential (ADP), acidification potential (AP), eutrophication potential (EP), global warming potential (GWP), ozone layer depletion potential (ODP), human toxicity potential (HTP), freshwater aquatic ecotoxicity potential (FEP), marine aquatic ecotoxicity potential (MEP), terrestrial ecotoxicity potential (TEP) and photochemical oxidation potential (POFP),

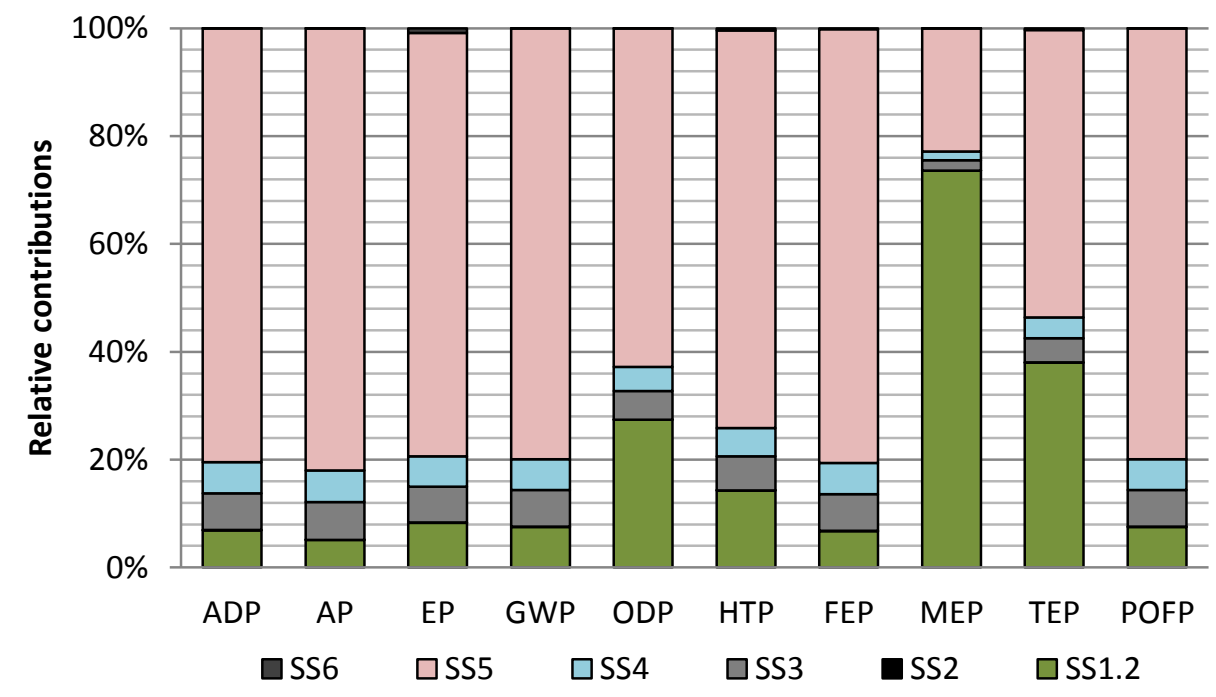


Figure 5. Distribution of impact burdens derived from SS1.2 between the different processes involved. Acronyms: abiotic depletion potential (ADP), acidification potential (AP), eutrophication potential (EP), global warming potential (GWP), ozone layer depletion potential (ODP), human toxicity potential (HTP), freshwater aquatic ecotoxicity potential (FEP), marine aquatic ecotoxicity potential (MEP), terrestrial ecotoxicity potential (TEP) and photochemical oxidation potential (POFP),

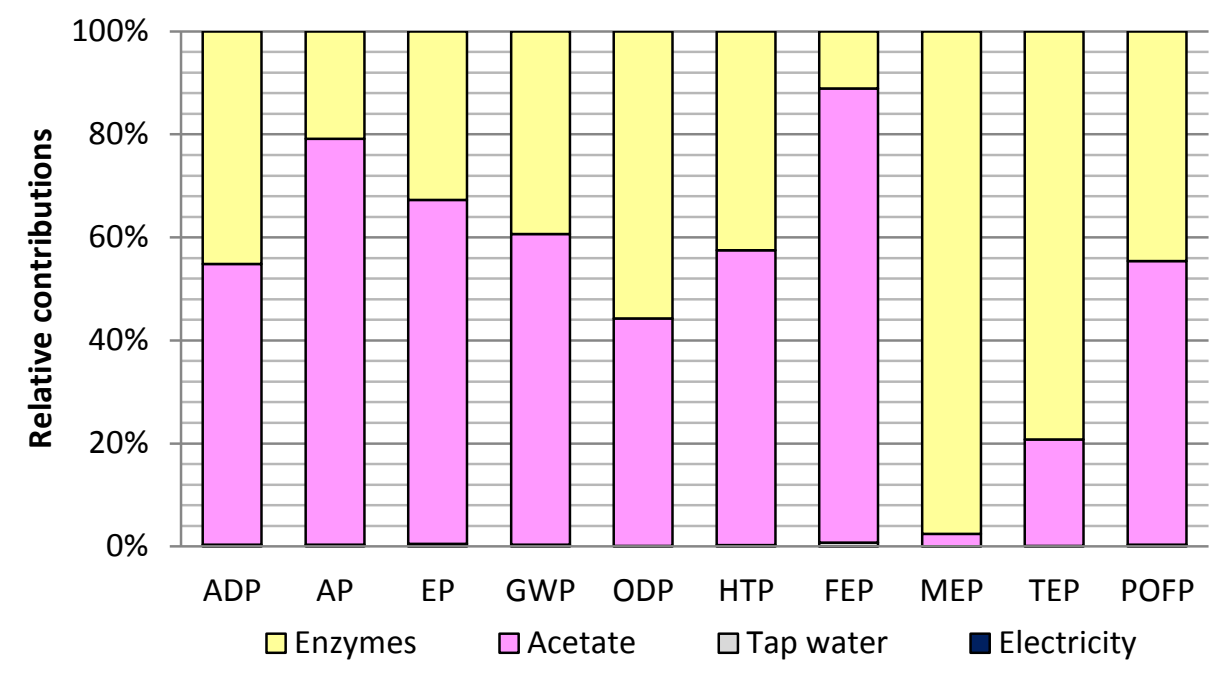

Figure 6. Distribution of electricity consumption per subsystems involved in each scenario. Scenario 1 - Autohydrolysis treatment; Scenario 2 - Enzymatic hydrolysis treatment. Acronyms: hydrolysis (SS1), centrifugation (SS2), concentration (SS3), diafiltration (SS4) and freeze-drying (SS5).

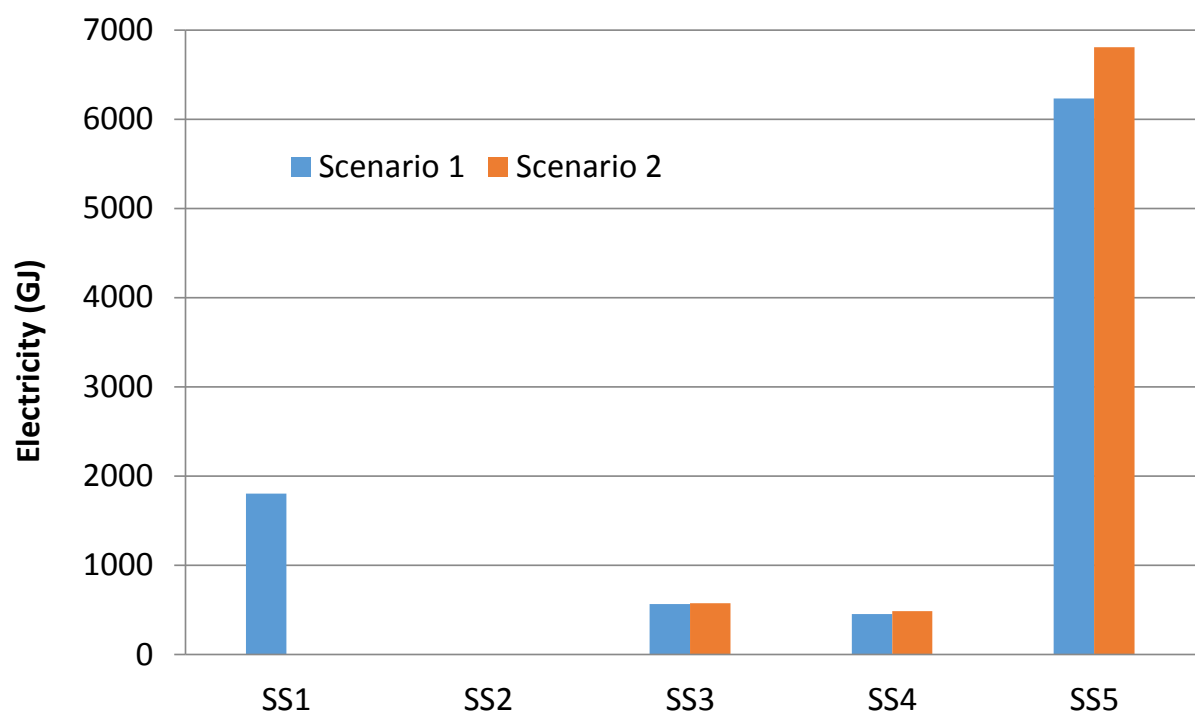


Figure 7. Comparative environmental profile considering $1 €$ of potential revenue as functional unit. Scenario 1 - Autohydrolysis treatment; Scenario 2 - Enzymatic hydrolysis treatment. Acronyms: abiotic depletion potential (ADP), global warming potential (GWP), ozone layer depletion potential (ODP), human toxicity potential (HTP), freshwater aquatic ecotoxicity potential (FEP), marine aquatic ecotoxicity potential (MEP), terrestrial ecotoxicity potential (TEP), photochemical oxidation potential (POFP), acidification potential (AP) and eutrophication potential $(E P)$,

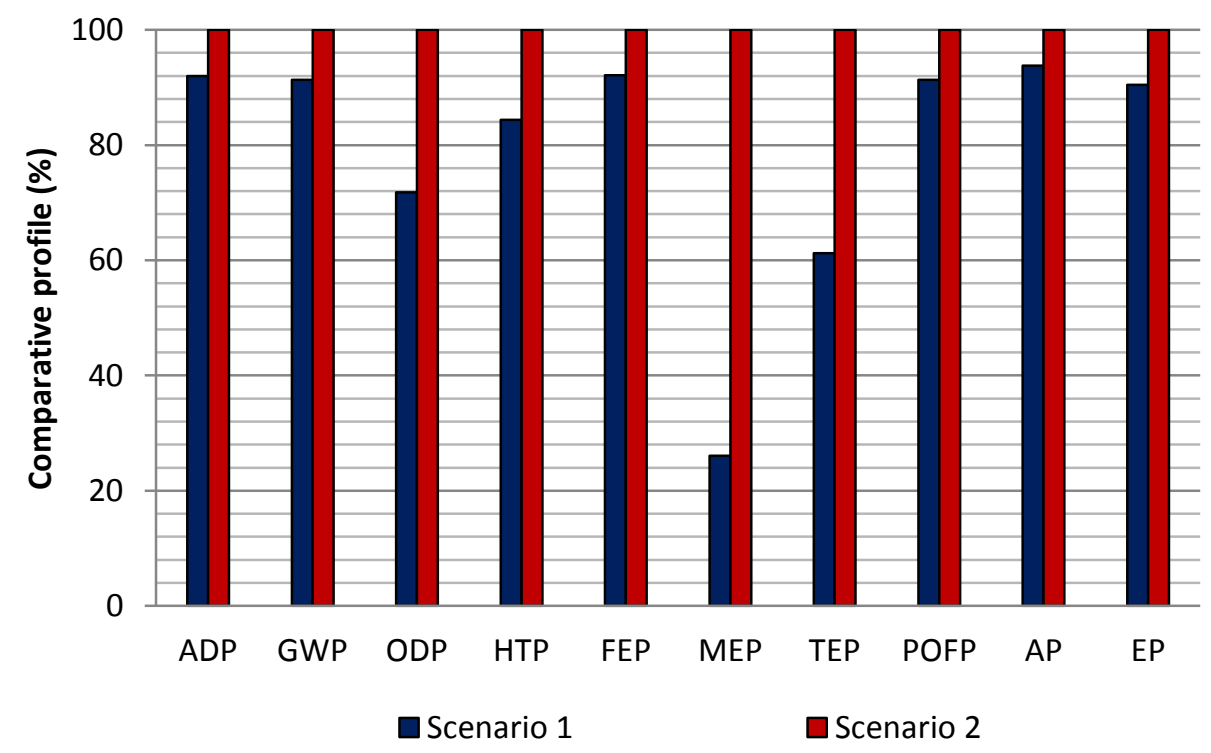


Table 1. Composition of liquid fraction (rich on pectic oligosaccharides) obtained by autohydrolysis treatment. 3

4

\begin{tabular}{lc}
\hline Component & Composition \\
\hline Monosaccharides & \\
\hline Glucose & $2.36 \mathrm{~g} \mathrm{~L}^{-1}$ \\
Galactose & $2.43 \mathrm{~g} \mathrm{~L}^{-1}$ \\
Arabinose & $0.39 \mathrm{~g} \mathrm{~L}^{-1}$ \\
\hline Pectin-derived oligosaccharides (POS) & \\
\hline GlcOS & $1.61 \mathrm{~g} \mathrm{~L}^{-1}$ \\
GalOS & $2.96 \mathrm{~g} \mathrm{~L}^{-1}$ \\
AraOS & $14.44 \mathrm{~g} \mathrm{~L}^{-1}$ \\
AcO & $2.06 \mathrm{~g} \mathrm{~L}^{-1}$ \\
OGalA & $11.86 \mathrm{~g} \mathrm{~L}^{-1}$ \\
\hline Volatile compounds & \\
\hline Acetic acid & $0.38 \mathrm{~g} \mathrm{~L}^{-1}$ \\
\hline Other non-volatile compounds & $8.21 \mathrm{~g} \mathrm{~L}^{-1}$ \\
\hline GlcOS = glucooligosaccharides; GalOS $=$ galactooligosaccharides; \\
AraOS = arabinooligosaccharides; AcO = acetyl substituents in \\
oligomers; OGalA = oligogalacturonides
\end{tabular}


9 Table 2. Composition of hydrolysates (rich on pectic oligosaccharides) obtained by enzymatic processing.

\begin{tabular}{lc}
\hline Component & Composition \\
\hline Monosaccharides & \\
\hline Glucose & $4.89 \mathrm{~g} \mathrm{~L}^{-1}$ \\
Galactose & $2.90 \mathrm{~g} \mathrm{~L}^{-1}$ \\
Galacaturonic acid & $3.50 \mathrm{~g} \mathrm{~L}^{-1}$ \\
Arabinose & $0.31 \mathrm{~g} \mathrm{~L}^{-1}$ \\
\hline Pectin-derived oligosaccharides (POS) & \\
\hline GlcOS & $6.59 \mathrm{~g} \mathrm{~L}^{-1}$ \\
GalOS & $3.02 \mathrm{~g} \mathrm{~L}^{-1}$ \\
AraOS & $11.21 \mathrm{~g} \mathrm{~L}^{-1}$ \\
AcO & $1.62 \mathrm{~g} \mathrm{~L}^{-1}$ \\
OGalA & $10.29 \mathrm{~g} \mathrm{~L}^{-1}$ \\
\hline Volatile compounds & $0.55 \mathrm{~g} \mathrm{~L}^{-1}$ \\
\hline Acetic acid & $13.87 \mathrm{~g} \mathrm{~L}^{-1}$ \\
\hline Other non-volatile compounds & \\
\hline GlcOS = glucooligosaccharides; GalOS $=$ galactooligosaccharides; \\
AraOS = arabinooligosaccharides; AcO = acetyl substituents in \\
oligomers; OGalA = oligogalacturonides
\end{tabular}


12 Table 3. Summary of main relevant inventory data for POS powder production from SBP under two valorising

13 scenarios: Scenario 1 - . Autohydrolysis treatment and Scenario 2 - Enzymatic hydrolysis treatment.

14

\begin{tabular}{l|l} 
Scenario 1 & Scenario 2 \\
\hline
\end{tabular}

\begin{tabular}{|c|c|c|}
\hline \multicolumn{3}{|l|}{ Inputs } \\
\hline \multicolumn{3}{|l|}{ Autohydrolisis } \\
\hline SBP (oven-dried) & $100 \mathrm{~kg}$ & -- \\
\hline Tap water & $945 \mathrm{~kg}$ & -- \\
\hline Electricity & $1802304 \mathrm{~kJ}$ & -- \\
\hline \multicolumn{3}{|l|}{ Enzymatic hydrolysis } \\
\hline SBP (oven-dried) & -- & $100 \mathrm{~kg}$ \\
\hline Tap water & -- & $912.5 \mathrm{~kg}$ \\
\hline Electricity & -- & $3192.3 \mathrm{~kJ}$ \\
\hline Vizcozyme & -- & $0.18 \mathrm{~kg}$ \\
\hline Cellulast & -- & $3.30 \mathrm{~kg}$ \\
\hline Acetate & -- & $30.0 \mathrm{~kg}$ \\
\hline \multicolumn{3}{|l|}{ Centrifugation } \\
\hline Electricity & $3510 \mathrm{~kJ}$ & $3510 \mathrm{~kJ}$ \\
\hline \multicolumn{3}{|l|}{ Concentration } \\
\hline Electricity & $567000 \mathrm{~kJ}$ & $577800 \mathrm{~kJ}$ \\
\hline \multicolumn{3}{|l|}{ Diafiltration } \\
\hline Electricity & $456300 \mathrm{~kJ}$ & $487820 \mathrm{~kJ}$ \\
\hline Tap water & $726.2 \mathrm{~kg}$ & $768.4 \mathrm{~kg}$ \\
\hline \multicolumn{3}{|l|}{ Freeze-drying } \\
\hline Electricity & $6234000 \mathrm{~kJ}$ & $6808000 \mathrm{~kJ}$ \\
\hline \multicolumn{3}{|l|}{ Outputs } \\
\hline POS powder from SS5 & $25.75 \mathrm{~kg}$ & $21.80 \mathrm{~kg}$ \\
\hline Purified POS & $25.40 \mathrm{~kg}$ & $20.60 \mathrm{~kg}$ \\
\hline Monosaccharides & $0.35 \mathrm{~kg}$ & $1.20 \mathrm{~kg}$ \\
\hline Wastewater to treatment (from SS3+SS4) & $1452.4 \mathrm{~kg}$ & $1536.8 \mathrm{~kg}$ \\
\hline Solid fraction from SS2 & $390.6 \mathrm{~kg}$ & $338.9 \mathrm{~kg}$ \\
\hline Cellulose (dry basis) & $14.60 \mathrm{~kg}$ & $6.70 \mathrm{~kg}$ \\
\hline Hemicellulose (dry basis) & $7.71 \mathrm{~kg}$ & $10.33 \mathrm{~kg}$ \\
\hline Lignin (dry basis) & $7.50 \mathrm{~kg}$ & $7.70 \mathrm{~kg}$ \\
\hline Uronic acids (dry basis) & $3.95 \mathrm{~kg}$ & $4.90 \mathrm{~kg}$ \\
\hline
\end{tabular}

15

16

17 
20 Table 4. Market prices and net economic yield expected for each valorising scenario as well as allocation factors based on economic allocation approach.

22

23

\begin{tabular}{l|ccc}
\multicolumn{3}{c}{} & \multicolumn{2}{c}{ Allocation factors } \\
\hline Co-products & Market price & Scenario 1 & Scenario 2 \\
\hline POS powder & $16.5 € \cdot \mathrm{g}^{-1}$ & $96.9 \%$ & $95.6 \%$ \\
Lignin & $302 € \cdot \mathrm{t}^{-1}$ & $0.0 \%$ & $0.0 \%$ \\
Cellulose & $686 € \cdot \mathrm{t}^{-1}$ & $0.0 \%$ & $0.0 \%$ \\
Hemicellulose & $102 € \cdot \mathrm{t}^{-1}$ & $0.0 \%$ & $0.0 \%$ \\
Uronic acids & $3.39 € \cdot \mathrm{g}^{-1}$ & $3.1 \%$ & $4.4 \%$ \\
\hline Economic yield & \multicolumn{3}{|}{} \\
Scenario 1 & $438,279 € \cdot$ batch $^{-1}$ & & \\
Scenario 2 & $376,319 € \cdot$ batch $^{-1}$ &
\end{tabular}

Table 5. Impact assessment characterisation values corresponding to the production of POS powder under two valorising schemes, per functional unit (100 kg of oven-dried SBP at the factory gate).

\begin{tabular}{|c|c|c|c|}
\hline Impact categories & & Scenario 1 & Scenario 2 \\
\hline Abiotic depletion potential & ADP & $9.45 \mathrm{~kg} \mathrm{Sb} \mathrm{eq}$ & $8.82 \mathrm{~kg} \mathrm{Sb}$ eq \\
\hline Global warming potential & GWP & $1299 \mathrm{~kg} \mathrm{CO}$ eq & $1221 \mathrm{~kg} \mathrm{CO}_{2}$ eq \\
\hline Acidification potential & $\mathrm{AP}$ & $12.37 \mathrm{~kg} \mathrm{SO}_{2} \mathrm{eq}$ & $11.33 \mathrm{~kg} \mathrm{SO}_{2} \mathrm{eq}$ \\
\hline Eutrophication potential & EP & $2.35 \mathrm{~kg} \mathrm{PO}_{4}^{-3} \mathrm{eq}$ & $2.23 \mathrm{~kg} \mathrm{PO}_{4}^{-3} \mathrm{eq}$ \\
\hline Ozone layer depletion potential & ODP & $8.23 \cdot 10^{-5} \mathrm{~kg} \mathrm{CFC}-11 \mathrm{eq}$ & $9.84 \cdot 10^{-5} \mathrm{~kg} \mathrm{CFC}-11 \mathrm{eq}$ \\
\hline Photochemical oxidation potential & POP & $4.51 \cdot 10^{-1} \mathrm{~kg} \mathrm{C}_{2} \mathrm{H}_{4}$ eq & $4.24 \cdot 10^{-1} \mathrm{~kg} \mathrm{C}_{2} \mathrm{H}_{4}$ eq \\
\hline Human toxicity potential & HTP & 235 kg 1,4-DB eq & 239 kg 1,4-DB eq \\
\hline Terrestrial ecotoxicity potential & TEP & $2.74 \cdot 10^{-1} \mathrm{~kg} 1,4-\mathrm{DB}$ eq & $3.84 \cdot 10^{-1} \mathrm{~kg} 1,4-\mathrm{DB}$ eq \\
\hline Freshwater aquatic ecotoxicity potential & FEP & $365 \mathrm{~kg} \mathrm{1,4-DB} \mathrm{eq}$ & $340 \mathrm{~kg}$ 1,4-DB eq \\
\hline Marine aquatic ecotoxicity potential & MEP & $1385 \mathrm{~kg} \mathrm{1,4-DB} \mathrm{eq}$ & $4458 \mathrm{~kg} \mathrm{1,4-DB} \mathrm{eq}$ \\
\hline
\end{tabular}

